\title{
Expression of Vesicular Nucleotide Transporter in the Mouse Retina
}

\author{
Satomi Moriyama and Miki Hiasa* \\ Department of Membrane Biochemistry, Okayama University Graduate School of Medicine, Dentistry and \\ Pharmaceutical Sciences; 1-1-1 Tsushima-naka, Kita-ku, Okayama 700-8530, Japan. \\ Received November 5, 2015; accepted December 18, 2015
}

\begin{abstract}
Vesicular nucleotide transporter (VNUT) is a membrane protein that is responsible for vesicular storage and subsequent vesicular release of nucleotides, such as ATP, and plays an essential role in purinergic chemical transmission. In the present study, we investigated whether VNUT is present in the rodent retina to define the site(s) of vesicular ATP release. In the mouse retina, reverse transcription polymerase chain reaction (RT-PCR) and immunological analyses using specific anti-VNUT antibodies indicated that VNUT is expressed as a polypeptide with an apparent molecular mass of $59 \mathrm{kDa}$. VNUT is widely distributed throughout the inner and outer retinal layers, particularly in the outer segment of photoreceptors, outer plexiform layer, inner plexiform layer, and ganglion cell layer. VNUT is colocalized with vesicular glutamate transporter 1 and synaptophysin in photoreceptor cells, while it is colocalized with vesicular $\gamma$-aminobutyric acid (GABA) transporter in amacrine cells and bipolar cells. VNUT is also present in astrocytes and Müller cells. The retina from VNUT knockout $\left(V N U T^{-1-}\right)$ mice showed the loss of VNUT immunoreactivity. The retinal membrane fraction took up radiolabeled ATP in diisothiocyanate stilbene disulfonic acid (DIDS)-, an inhibitor of VNUT, and bafilomycin A1-, a vacuolar adenosine triphosphatase (ATPase) inhibitor, in a sensitive manner, while membranes from $V N U T^{-1-}$ mice showed the loss of DIDS-sensitive ATP uptake. Taken together, these results indicate that functional VNUT is expressed in the rodent retina and suggest that ATP is released from photoreceptor cells, bipolar cells, amacrine cells, and astrocytes as well as Müller cells to initiate purinergic chemical transmission.
\end{abstract}

Key words ATP; vesicular nucleotide transporter; retina; photoreceptor cell; amacrine cell; bipolar cell

The retina is a photoreceptive organ in which photosignals received by photoreceptor cells are transmitted to the optic nerve mainly through glutamatergic and $\gamma$-aminobutyric acid (GABA)ergic chemical transmission. There is, however, evidence that ATP and adenosine are involved as intercellular transmitters and play roles in various functions in the retina. ${ }^{1-3)}$

The retina has been reported to express various purinoceptors and enzymes involved in ATP hydrolysis., ${ }^{2,3)}$ Photoreceptor cells express P2X2, P2X7, and P2Y1, 2, 4, and 6 receptors. $^{2)}$ P2X7 is localized presynaptically to rod and cone pedicles, and a functional study showed that $3^{\prime}-O-(4-$ benzoyl)benzoyl-ATP (BzATP) increases the amplitude of the $\alpha$-wave, suggesting a neuromodulatory role of purinergic neurotransmission. ${ }^{4)}$ Intravitreal injection of ATP caused rapid loss of photoreceptors, which was reduced by coinjection of the P2X antagonist, pyridoxalphosphate-6-azophenyl-2',4'disulfonic acid (PPADS), suggesting the involvement of purinergic chemical transmission in photoreceptor integrity. ${ }^{5)} \mathrm{Bi}$ polar cells and horizontal cells also express P2X3-5 and 7 and $\mathrm{P} 2 \mathrm{Y} 1,2$, 6, and $\mathrm{P} 2 \mathrm{X} 7$, respectively. ${ }^{2)}$ Ganglion cells express both P2Xs and P2Y. ${ }^{6}$ Stimulation of P2X7, with BzATP, an agonist of $\mathrm{P} 2 \mathrm{X} 7$, induced death of the isolated ganglion cells through increases in intracellular $\mathrm{Ca}^{2+}{ }^{2}$ ) Loss of ganglion cells in vivo was also observed following injection of BzATP into the retina. ${ }^{7)}$ It has also been reported that $\mathrm{A} 1$ and $\mathrm{A} 3$ receptors are involved in neuroprotection of ganglion cells. ${ }^{8-11)}$ Müller cells, retinal glial cells with numerous fine processes, which may make contact with neurons and non-neuronal cells, also express P2X7 and P2Y1, and their stimulation by specific agonists results in increased DNA synthesis and elicitation of the $\mathrm{Ca}^{2+}$ response, respectively. ${ }^{12)}$
Extracellular ATP and its degradation product, adenosine, may trigger purinergic responses. In fact, Müller cells were reported to release ATP in a $\mathrm{Ca}^{2+}$-dependent manner. ${ }^{9)}$ It was also reported that cultured chick retinal neurons took up radiolabeled ATP then released ATP. ${ }^{13)}$ The co-release of ATP and acetylcholine from cholinergic amacrine cells was reported. ${ }^{14)}$ Retina pigment epithelium (RPE) cells also release ATP to activate photoreceptor cells. ${ }^{15,16)}$ Although these results clearly indicated that retinal cells release ATP, it is still far less understood how and where ATP is released.

Vesicular nucleotide transporter (VNUT), the last member of the SLC17 anion transporter family, is an active transporter of nucleotides such as ATP and ADP in the endomembrane vesicles, the driving force for which is an electrochemical gradient of protons across the membranes established by vacuolar $\mathrm{H}^{+}$-ATPase. ${ }^{17,18)}$ VNUT is present in various ATP-storing secretory vesicles, such as adrenal chromaffin granules, insulin granules of islet $\beta$ cells, glutamate-containing synaptic vesicles of hippocampal neurons, platelet granules, airway epithelial mucin granules, and Glucagon-like peptide-1 (GLP-1)containing granules of intestinal L cells. ${ }^{17,19-24)} V N U T^{-/-}$mice were shown to lose vesicular ATP content and vesicular ATP release, resulting in dissection of purinergic chemical transmission in vivo. ${ }^{19)}$ Thus, VNUT is primarily responsible for vesicular ATP storage and release, and plays an essential role in purinergic chemical transmission.

As VNUT is regarded as a potential and useful marker for sites of vesicular storage and secretion of ATP, we investigated the expression and localization of VNUT protein in the mouse retina with special reference to the retina of $V N U T^{-/-}$ mice. Here, we present biochemical and immunohistochemical evidence for the presence of VNUT in the retina. 


\section{MATERIALS AND METHODS}

Antibodies The immunological specificities of rabbit polyclonal antibodies against VNUT rabbit polyclonal antibodies prepared in-house were determined previously. ${ }^{17)}$ The following antibodies were obtained commercially: antisynaptophysin mouse monoclonal (Progen, Heidelberg, Germany), anti-PSD95 mouse monoclonal (Abcam, Cambridge, U.K.), anti-vesicular glutamate transporter 1 (VGLUT1) mouse monoclonal (Synaptic Systems, Goettingen, Germany), antivesicular GABA transporter (VGAT) guinea pig polyclonal antibodies (Merck Millipore, Darmstadt, Germany), anti-Glutamine Synthetase mouse monoclonal (Merck Millipore), and anti-glial fibrillary acidic protein (GFAP) mouse monoclonal (Thermo Fisher Scientific, Waltham, MA, U.S.A.).

Animals Male C57BL/6 mice were obtained from Japan SLC (Shizuoka, Japan). $V N U T^{-/-}$mice were generated by gene disruption. ${ }^{19)}$ All animal procedures and care were approved by the Institutional Animal Care and Use Committee, and were carried out in accordance with the guidelines of Okayama University.

Reverse Transcription Polymerase Chain Reaction (RTPCR) Analysis Mouse total RNA was extracted from the retina using ISOGEN (Nippon Gene, Tokyo, Japan) according to the manufacturer's instructions. cDNA was generated from total RNA with a reverse transcriptase kit (Toyobo, Osaka, Japan) using $1 \mu \mathrm{g}$ of total RNA as the template. The RT-PCR conditions included an initial denaturation step of $95^{\circ} \mathrm{C}$ for $1 \mathrm{~min}$ followed by 33 cycles of $95^{\circ} \mathrm{C}$ for $30 \mathrm{~s}, 64^{\circ} \mathrm{C}$ for $30 \mathrm{~s}$, and $72^{\circ} \mathrm{C}$ for $1 \mathrm{~min}$. The following primers were used: mouse VNUT, GGT CTGCCAAGG TGT CTA C (forward), GAC TGA TAAGGCGGTCGGAG (reverse), glyceraldehyde 3-phosphate dehydrogenase (G3PDH), TGT GTCCGTCGT GGA TCTGA (forward) and TTGCTGTTGAAGTCGCAGGAG (reverse).

Immunofluorescence Microscopy Indirect immunofluorescence microscopy was performed as described previously. ${ }^{25)}$ Briefly, mice were anesthetized with ether and then perfused intracardially with saline, followed by $4 \%$ paraformaldehyde in $0.1 \mathrm{M}$ phosphate buffer $(\mathrm{pH}$ 7.4). The retina was isolated, and frozen sections were prepared. The first antibody treatment was performed with anti-mouse VNUT antibody diluted 1:200 in phosphate buffered saline (PBS) containing $0.5 \%$ bovine serum albumin (BSA) for $1 \mathrm{~h}$ at room temperature. Washing and secondary antibody treatment was performed according to the published procedures. ${ }^{25)}$ The specimens were observed under an Olympus FV 300 confocal laser microscope.

Western Blotting Analysis For immunoblotting, organs were suspended in $20 \mathrm{~mL}$ of $10 \mathrm{~mm} 3-(N$-morpholino)propane sulfonic acid (MOPS)-Tris ( $\mathrm{pH} 7.0$ ) containing $0.3 \mathrm{M}$ sucrose, $5 \mathrm{~mm}$ ethylenediaminetetraacetic acid (EDTA), $10 \mu \mathrm{g} / \mathrm{mL}$ pepstatin A, and $10 \mu \mathrm{g} / \mathrm{mL}$ leupeptin, and then homogenized with a Dounce homogenizer. The homogenate was centrifuged at $1000 \times \boldsymbol{g}$ for $10 \mathrm{~min}$. The resulting supernatant was centrifuged at $160000 \times \boldsymbol{g}$ for $1 \mathrm{~h}$. Then, the pellets were suspended with the same buffer and the resultant solution was centrifuged at $10000 \times \boldsymbol{g}$ for $10 \mathrm{~min}$. The resultant supernatant was then centrifuged at $160000 \times \mathbf{g}$ for $1 \mathrm{~h}$. The pellet (membrane vesicle fraction) was suspended in the same buffer, and then denatured with sample buffer containing $1 \%$ sodium dodecyl sulfate (SDS) and 10\% $\beta$-mercaptoethanol. Polyacrylamide gel electrophoresis and Western blotting were performed as described previously. ${ }^{25}$ Immunoreactivity was visualized by enhanced chemiluminescence (ECL) amplification according to the manufacturer's protocol (GE Healthcare, Buckinghamshire, U.K.). Protein concentrations were determined with a protein assay kit (Bio-Rad, Hercules, CA, U.S.A.) with BSA as a standard.

ATP Uptake Membrane vesicles ( $50 \mu \mathrm{g}$ protein per assay) were suspended in $120 \mu \mathrm{L}$ of $20 \mathrm{~mm}$ MOPS-Tris ( $\mathrm{pH} 7.0$ ), $0.3 \mathrm{M}$ sucrose, $2 \mathrm{~mm}$ magnesium acetate, $4 \mathrm{~mm} \mathrm{KCl,} 5 \mu \mathrm{M}$ oligomycin, and $1 \mu \mathrm{M}$ atractyloside, and incubated for $5 \mathrm{~min}$ at $30^{\circ} \mathrm{C}$. Oligomycin and atractyloside were added to exclude any possible participation of ATP uptake by contaminating mitochondrial membrane (corresponding to $<10 \%$ of total activity under the assay conditions used). The assay was initiated by addition of $2 \mathrm{~mm}\left[2.8-{ }^{3} \mathrm{H}\right]$ ATP $(0.05 \mathrm{MBq} / \mu \mathrm{mol}) ; 100-\mu \mathrm{L}$ aliquots were taken at the times indicated and filtered through $0.45 \mu \mathrm{m}$ nitrocellulose filters (Merck Millipore). After washing with $6 \mathrm{~mL}$ of cold buffer containing $20 \mathrm{~mm}$ MOPS-Tris ( $\mathrm{pH} 7.0$ ), $0.3 \mathrm{M} \mathrm{su}-$ crose, $2 \mathrm{~mm}$ magnesium acetate, and $4 \mathrm{~mm} \mathrm{KCl}$, the remaining radioactivity on the filters was counted with a liquid scintillation counter (PerkinElmer, Inc., Waltham, MA, U.S.A.). More than $90 \%$ of the radioactive ATP was not degraded under the assay conditions employed.

Data Analysis Numerical values are shown as the mean \pm standard error of the mean (S.E.M.) $(n=3-4)$. Statistical significance was determined by Student's $t$-test. $*<0.05$, $* * *<0.001$

\section{RESULTS}

Expression of VNUT in the Retina First, we examined whether VNUT is expressed in the mouse retina. In RT-PCR analyses, a 523-bp VNUT-specific transcript was amplified in the wild-type retina, whereas the transcript was not observed in $V N U T^{-1-}$ mice, confirming VNUT gene expression in the retina $^{26)}$ (Fig. 1A). Western blotting analysis with the membrane fraction of the whole retina revealed a VNUT counterpart with apparent molecular mass of $59 \mathrm{kDa}$, while there was no counterpart in the retina membrane fraction isolated from $V N U T^{-/-}$mice (Fig. 1B). The reasons for the occurrence of smear signals with higher molecular masses than that of VNUT counterparts were discussed later. Similar amounts of immunological counterparts of synaptophysin as well as VGLUT1 were observed in the retinal membranes from both wild-type and $V N U T^{-1-}$ mice (Fig. 1B). These results indicated the presence of a VNUT counterpart in the mouse retina.

Localization of VNUT Immunohistochemical analysis indicated the presence of VNUT in the mouse retina. As shown in Fig. 1c, the VNUT immunoreactivity was widely distributed throughout the outer and inner layers of the retina, while only background level of immunoreactivity was observed in the $V N U T^{-1-}$ mouse retina. Robust VNUT immunoreactivities were located in the outer segments of photoreceptors (OS), outer plexiform layer (OPL), inner plexiform layer (IPL), and ganglion cell layer (GCL). VNUT immunoreactivity was also found in the inner nuclear layer (INL). In contrast, weak VNUT immunoreactivity was found in the outer nuclear layer $(\mathrm{ONL})$.

To define the sites of VNUT localization more precisely, we 
(A)

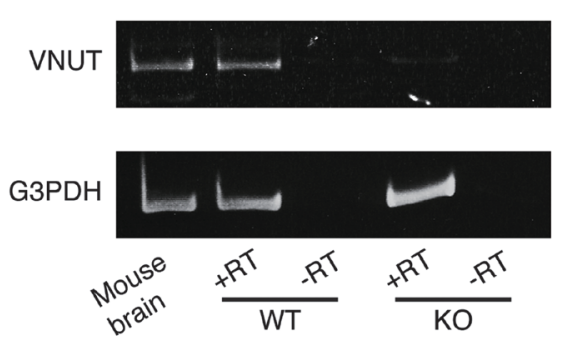

(B)

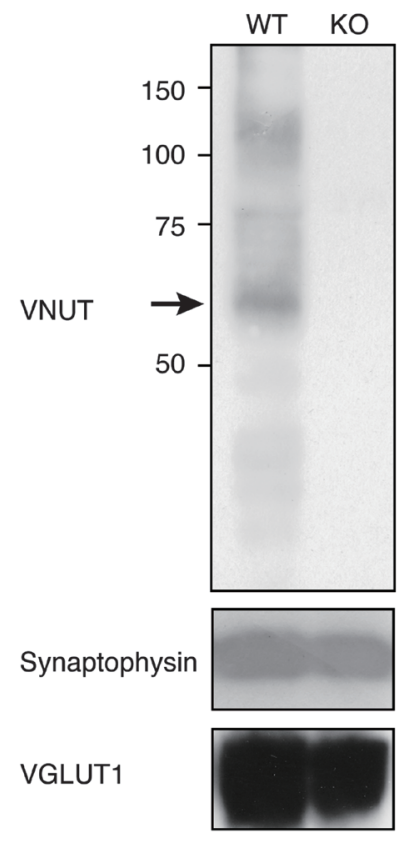

(C)

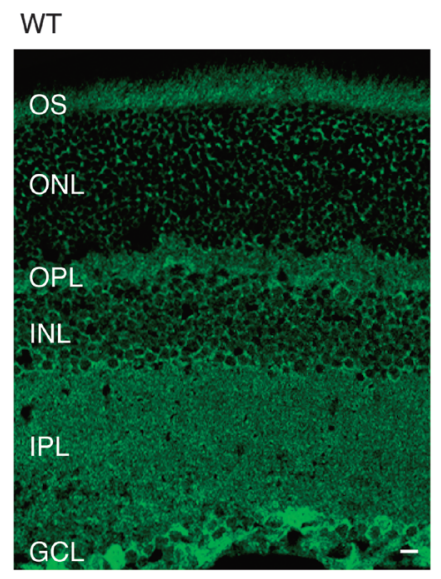

KO

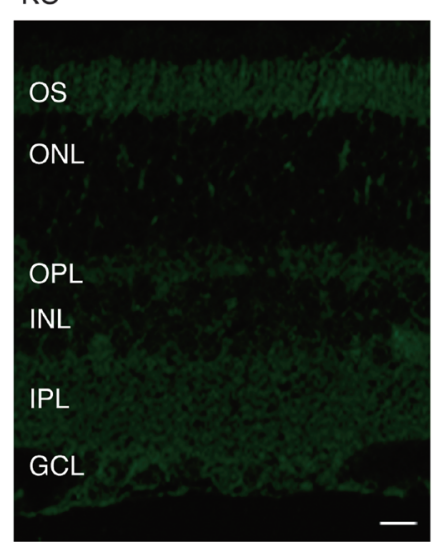

Fig. 1. VNUT Is Expressed in the Mouse Retina

(A) RT-PCR analysis was performed to examine expression of VNUT mRNAs in the mouse retina (523 bp, top). The PCR product from brain mRNA is shown as a positive control. Glyceraldehyde-3-phosphate dehydrogenase (G3PDH) gene expression is also shown as an RNA quality control (150 bp, bottom). (B) Immunoblotting analysis with anti-VNUT rabbit polyclonal antibodies. After dissociation with sodium dodecyl sulfate (SDS) sample buffer, membrane fractions were subjected to $10 \%$ SDS-polyacrylamide gel electrophoresis (SDS-PAGE) and then Western blotting analysis was conducted with anti-VNUT antibodies. Lane 1, retinal membrane from wildtype $(30 \mu \mathrm{g})$, and lane 2 , retinal membrane from VNUT knockout mice $(30 \mu \mathrm{g})$ were examined. The arrow indicates the position of VNUT. Similar immunoblots were conducted using antibodies against synaptophysin and VGLUT1. (C) Immunohistochemical detection of VNUT. Sections of the retina from wild-type and $V N U T^{-/-}$mice were immunostained as described in Materials and Methods. Bar $=10 \mu \mathrm{m}$.

next conducted double-labeling immunohistochemistry. The results indicated a punctate VNUT distribution colocalized with synaptophysin, a synaptic vesicle marker, and PSD-95 in the OPL, suggesting that VNUT was located on the terminals of photoreceptor cells (Figs. 2A, B). The colocalization of VNUT and synaptophysin in IPL suggested that VNUT was located on the terminals of bipolar cells and amacrine cells. VNUT was colocalized with VGLUT1, a glutamatergic neuronal synaptic marker, in the OPL, and VGAT, a GABAergic neuronal synaptic marker, in the IPL (Figs. 2C, D). VNUT was also colocalized with glutamine synthetase-labeled Müller cells in the IPL (Fig. 2E). Interestingly, GFAP labeling of astrocytes, which was predominantly localized in the GCL, was colocalized with VNUT (Fig. 2F). Taken together, these observations indicated that VNUT was located in the terminals of photoreceptor cells, bipolar cells, amacrine cells, Müller cells, and astrocytes.

Uptake of ATP Finally, we assessed the uptake of radiolabeled ATP by retinal membrane fraction. As shown in Fig. 3 , retinal membrane vesicles prepared from wild-type mice took up ATP, which was inhibited by DIDS, a VNUT inhibitor, ${ }^{18)}$ as well as bafilomycin A1, a specific inhibitor of vacuolar ATPase. The retinal membrane vesicles prepared from $V N U T^{-/-}$mice exhibited the background level of ATP uptake (Fig. 3).

\section{DISCUSSION}

In purinergic chemical transmission, ATP is stored and released by a vesicular mechanism, and the released ATP and its hydrolysis product adenosine bind to the respective purinoceptors, causing the secondary purinergic response. Here, we presented compelling evidence that functional VNUT is expressed in the mouse retina using biochemical and immunological techniques with special reference to the VNUT knockout mouse, and provided information regarding where ATP is stored and released.

We found that VNUT is widely distributed throughout the retina. VNUT is expressed in photoreceptor cells, amacrine cells, bipolar cells, astrocytes, and Müller cells, suggest- 

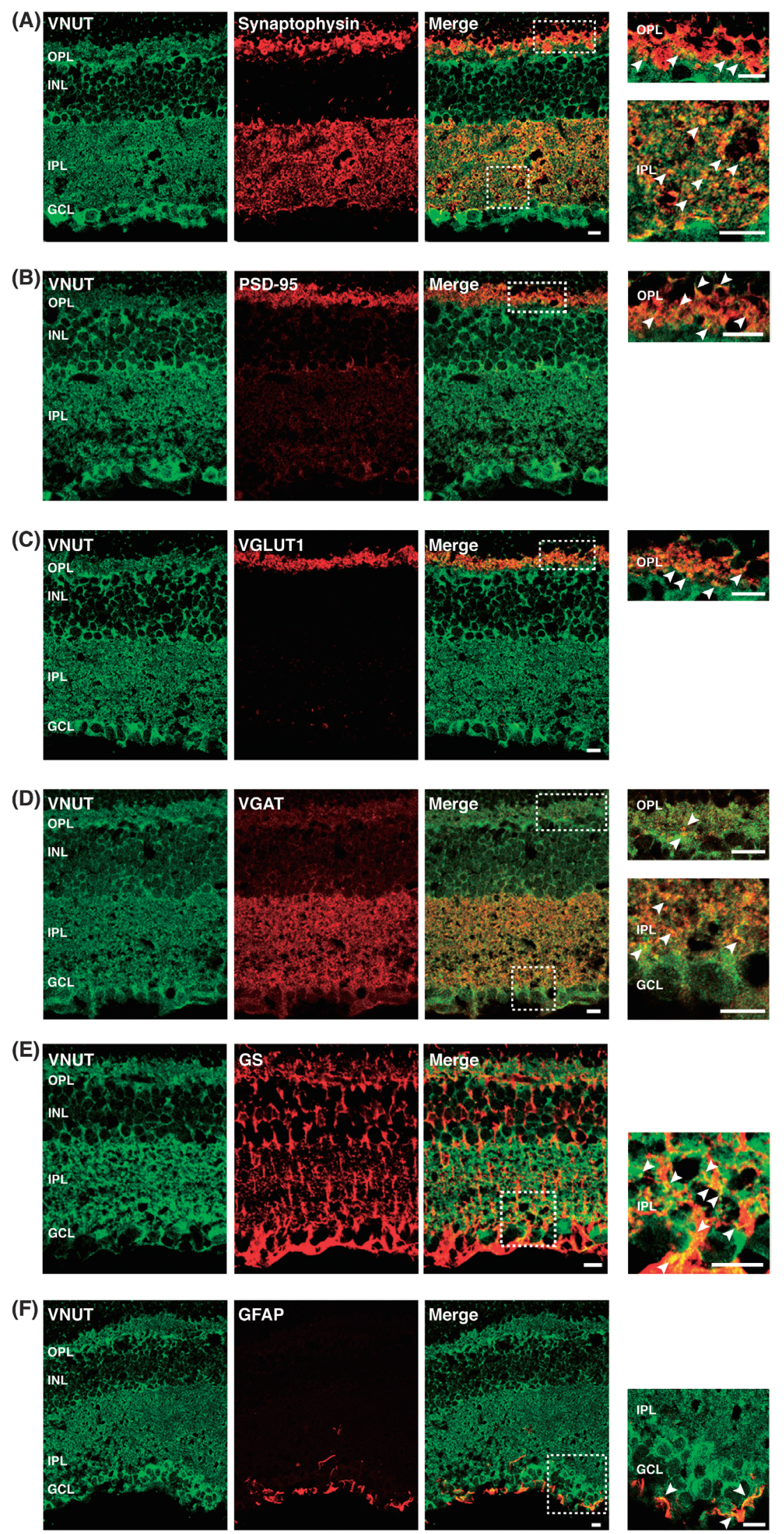

Fig. 2. Distribution of VNUT Protein in the Retina

Sections of the retina were doubly immunostained with antibodies against VNUT (green) and markers (red): synaptophysin, PSD95, VGLUT1, VGAT, GS, and GFAP. Merged pictures are also shown. The marked areas are enlarged in the panels on the right. Arrowheads indicate merged regions. Bars $=10 \mu \mathrm{m}$. 


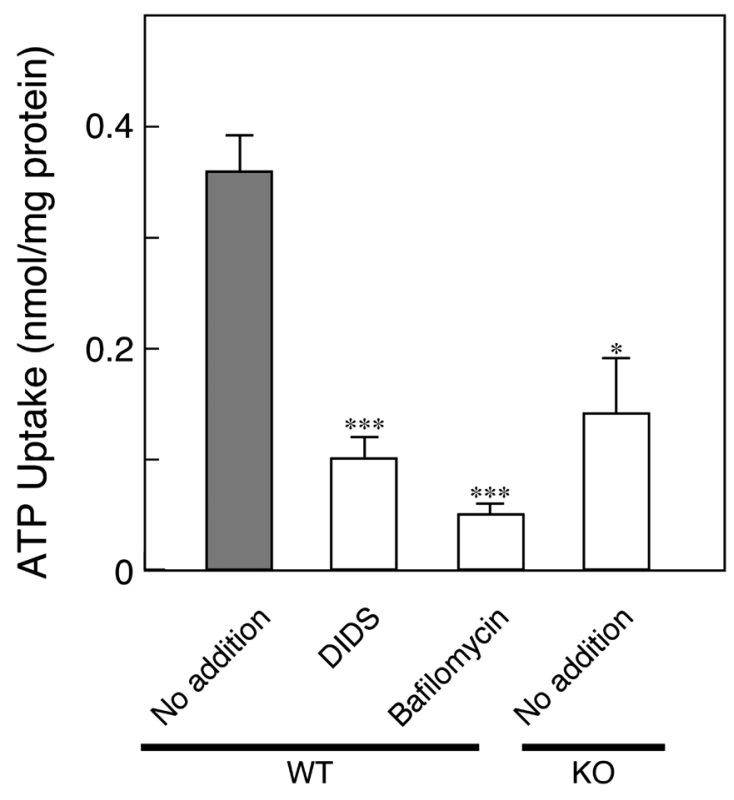

Fig. 3. Uptake of ATP by Retinal Membrane Vesicles

ATP uptake by retinal membrane fraction $(50 \mu \mathrm{g})$ from wild-type or $V N U T^{-1}$ knockout mice was examined in the absence or presence of DIDS $(10 \mu \mathrm{M})$ or bafilomycin A1 (50 nM) as indicated.

ing that almost all cell types are involved in vesicular ATP release in the mouse retina. On SDS gel electrophoresis followed by Western analysis, VNUT immunoreactivities exhibited many smear signals, which completely disappeared in the retina from $V N U T^{-/-}$mice (Fig. 1B). We believed that these bands represent VNUT proteins due to formation of dimer or trimmers, interaction of other proteins, and glycosylation as observed in tissues- or cell-dependent fashion. ${ }^{20,22,24)}$ The colocalization of VNUT with synaptophysin suggested that VNUT is associated with synaptic vesicles in photoreceptor cells, amacrine cells, and bipolar cells. The colocalization of VNUT with VGLUT1 in photoreceptor cells and VGAT in amacrine cells supported this conclusion. At present, we do not know whether VNUT is associated with VGLUT- or VGAT-containing synaptic vesicles, and further studies using immunoelectron microscopy will be necessary. In this respect, it is noteworthy that cholinergic amacrine cells corelease ATP and acetylcholine. ${ }^{14,27)}$ As acetylcholine is accumulated in synaptic vesicles through an active transport mechanism like ATP by vesicular acetylcholine transporter (VAChT), in these cells, it is expected that VNUT and VAChT would colocalize within the same vesicles. It is also noteworthy that retinal glial cells, astrocytes, and Müller cells express VNUT, strongly suggesting that these cells also secrete ATP by a vesicular mechanism. This is the case with the brain glial cells-VNUT is expressed in microglia ${ }^{28}$ and astrocytes, although little information is available regarding the VNUT-containing organelles in glial cells. Taking into consideration the expression pattern of VNUT, we can determine the possible ATP-mediated signaling pathways in the retina.

Our conclusion regarding the expression and distribution of VNUT is strengthened by the results of comparative analysis with $V N U T^{-/-}$mice. Only background levels of both VNUT immunoreactivity and ATP uptake activity were observed in $V N U T^{-1-}$ mice. We have already shown that $V N U T^{-/-}$mice have impaired vesicular ATP storage and release from neurons and endocrine cells, thus allowing dissection of purinergic signal transmission in these cells. ${ }^{19)}$ Therefore, it is expected that vesicular ATP release from retinal cells should be impaired in $V N U T^{-/-}$mice, resulting in disappearance of the purinergic secondary response. Purinergic chemical transmission was suggested to be involved in apoptosis of photoreceptors and ganglion cells, ${ }^{2,3,6,29)}$ volume regulation, ${ }^{30,31)}$ and contraction of pericytes in retinal microvessels. ${ }^{32,33)}$ Due to technical limitations in the present study, we could not examine whether vesicular ATP release is also impaired in the retinal cells of $V N U T^{-/-}$mice. Further studies using $V N U T^{-/-}$mice will be helpful to elucidate the roles of VNUT or vesicular ATP release in the pathophysiology of the retina.

Of course, it should be noted that ATP-penetrating ion channels, such as hemichannels and pannexins, are present in retinal cells and involved in ATP release from these cells, ${ }^{34)}$ and mechanosensitive ATP is released from optic nerve head astrocytes through pannexin hemichannel. ${ }^{35)}$ Taking expression and operation of VNUT as well as the mechanosensitive ATP-penetrating channels into consideration, we assume that two different mechanisms, i.e., vesicular ATP accumulation and mechanosensitive ATP-penetrating channels, may participate in release of ATP. Further quantitative studies are necessary to determine the fraction of vesicular ATP in purinergic chemical transmission in the retina.

In summary, we concluded that functional VNUT is widely present in the rodent retina. The present study provides a good starting point to obtain precise information about when, where, and how purinergic chemical transmission is initiated in the retina.

Acknowledgments This work was supported in part by Grants-in-Aid for Scientific Research on Innovative Areas (No. 26117514) and the Takeda Science Foundation.

Conflict of Interest The authors declare no conflict of interest.

\section{REFERENCES}

1) Burnstock G. Physiology and pathophysiology of purinergic neurotransmission. Physiol. Rev., 87, 659-797 (2007).

2) Guzman-Aranguez A, Santano C, Martin-Gil A, Fonseca B, Pintor J. Nucleotides in the eye: Focus on functional aspects and therapeutic perspectives. J. Pharmacol. Exp. Ther., 345, 331-341 (2013).

3) Sanderson J, Dartt DA, Trinkaus-Randall V, Pintor J, Civan MM, Delamere NA, Fletcher EL, Salt TE, Grosche A, Mitchell CH. Purines in the eye: recent evidence for the physiological and pathological role of purines in the RPE, retinal neurons, astrocytes, Müller cells, lens, trabecular meshwork, cornea and lacrimal gland. Exp. Eye Res., 127, 270-279 (2014).

4) Puthussery $T$, Yee P, Vingrys AJ, Fletcher EL. Evidence for the involvement of purinergic $\mathrm{P} 2 \mathrm{X}$ receptors in outer retinal processing. Eur. J. Neurosci., 24, 7-19 (2006).

5) Puthussery T, Fletcher E. Extracellular ATP induces retinal photoreceptor apoptosis through activation of purinoceptors in rodents. $J$. Comp. Neurol., 513, 430-440 (2009).

6) Zhang X, Zhang M, Laties AM, Mitchell CH. Stimulation of P2X7 receptors elevates $\mathrm{Ca}^{2+}$ and kills retinal ganglion cells. Invest. Ophthalmol. Vis. Sci., 46, 2183-2191 (2005).

7) $\mathrm{Hu} \mathrm{H}$, Lu W, Zhang M, Zhang X, Argall AJ, Patel S, Lee GE, Kim YC, Jacobson KA, Laties AM, Mitchell CH. Stimulation of the $\mathrm{P} 2 \mathrm{X} 7$ receptor kills rat retinal ganglion cells in vivo. Exp. Eye Res., 
91, 425-432 (2010).

8) Hartwick AT, Lalonde MR, Barnes S, Baldridge WH. Adenosine A1-receptor modulation of glutamate-induced calcium influx in rat retinal ganglion cells. Invest. Ophthalmol. Vis. Sci., 45, 3740-3748 (2004).

9) Newman EA. Glial cell inhibition of neurons by release of ATP. $J$. Neurosci., 23, 1659-1666 (2003)

10) Newman EA. Glial modulation of synaptic transmission in the retina. Glia, 47, 268-274 (2004).

11) Zhang M, Budak MT, Lu W, Khurana TS, Zhang X, Laties AM, Mitchell $\mathrm{CH}$. Identification of the A3 adenosine receptor in rat retinal ganglion cells. Mol. Vis., 12, 937-948 (2006).

12) Wurm A, Pannicke T, Iandiev I, Francke M, Hollborn M, Wiedemann P, Reichenbach A, Osborne NN, Bringmann A. Purinergic signaling involved in Müller cell function in the mammalian retina. Prog. Retin. Eye Res., 30, 324-342 (2011).

13) Blazynski C, Perez MT. Adenosine in vertebrate retina: localization, receptor characterization, and function. Cell. Mol. Neurobiol., 11, 463-484 (1991).

14) Neal M, Cunningham J. Modulation by endogenous ATP of the light-evoked release of ACh from retinal cholinergic neurones. $\mathrm{Br}$. J. Pharmacol., 113, 1085-1087 (1994).

15) Reigada D, Lu W, Mitchell CH. Glutamate acts at NMDA receptors on fresh bovine and on cultured human retinal pigment epithelial cells to trigger release of ATP. J. Physiol., 575, 707-720 (2006).

16) Mitchell $\mathrm{CH}$, Reigada D. Purinergic signalling in the subretinal space: a role in the communication between the retina and the RPE. Purinergic Signal., 4, 101-107 (2008).

17) Sawada K, Echigo N, Juge N, Miyaji T, Otsuka M, Omote H, Yamamoto A, Moriyama Y. Identification of a vesicular nucleotide transporter. Proc. Natl. Acad. Sci. U.S.A., 105, 5683-5686 (2008).

18) Omote H, Miyaji T, Hiasa M, Juge N, Moriyama Y. Use of recombinant protein structure, function, and drug interactions of transporters in the post-genome era. Ann. Rev. Pharmacol. Toxicol., 56, 385-402 (2016).

19) Sakamoto S, Miyaji T, Hiasa M, Ichikawa R, Uematsu A, Iwatsuki K, Shibata A, Uneyama H, Takayanagi R, Yamamoto A, Omote H, Nomura M, Moriyama Y. Impairment of vesicular ATP release affects glucose metabolism and increases insulin sensitivity. Sci. Rep., 4, 6689 (2014).

20) Larsson M, Sawada K, Morland C, Hiasa M, Ormel L, Moriyama Y, Gundersen V. Functional and anatomical identification of a vesicular transporter mediating neuronal ATP release. Cereb. Cortex, 22, 1203-1214 (2012).

21) Sesma JI, Kreda SM, Okada SF, van Heusden C, Moussa L, Jones LC, O’Neal WK, Togawa N, Hiasa M, Moriyama Y, Lazarowski ER. Vesicular nucleotide transporter regulates the nucleotide content in airway epithelial mucin granules. Am. J. Physiol. Cell Physiol., 304, C976-C984 (2013).

22) Hiasa M, Togawa N, Miyaji T, Omote H, Yamamoto A, Moriyama Y. Essential role of vesicular nucleotide transporter in vesicular storage and release of nucleotides in platelets. Physiol. Rep., 2, e12034 (2014a).

23) Hiasa M, Togawa N, Moriyama Y. Vesicular nucleotide transport: a brief history and the vesicular nucleotide transporter as a target for drug development. Curr. Pharm. Des., 20, 2745-2749 (2014b).

24) Harada Y, Hiasa M. Immunological identification of vesicular nucleotide transporter in intestinal L cells. Biol. Pharm. Bull., 37, 1090-1095 (2014).

25) Hayashi M, Yamada H, Uehara S, Morimoto R, Muroyama A, Yatsushiro S, Takeda J, Yamamoto A, Moriyama Y. Secretory granule-mediated co-secretion of L-glutamate and glucagon triggers glutamatergic signal transmission in islets of Langerhaus. J. Biol. Chem., 278, 1966-1974 (2003).

26) Vessey KA, Fletcher EL. Rod and cone pathway signalling is altered in the P2X7 receptor knock out mouse. PLoS ONE, 7, e29990 (2012).

27) Santos PF, Caramelo OL, Carvalho AP, Duarte CB. Characterization of ATP release from cultures enriched in cholinergic amacrinelike neurons. J. Neurobiol., 41, 340-348 (1999).

28) Shinozaki Y, Nomura M, Iwatsuki K, Moriyama Y, Gachet C, Koizumi S. Microglia trigger astrocyte-mediated neuroprotection via purinergic gliotransmission. Sci. Rep., 4, 4329 (2014).

29) Notomi S, Hisatomi T, Kanemaru T, Takeda A, Ikeda Y, Enaida H, Kroemer G, Ishibashi T. Critical involvement of extracellular ATP acting on P2RX7 purinergic receptors in photoreceptor cell death. Am. J. Pathol., 179, 2798-2809 (2011).

30) Uckermann O, Wolf A, Kutzera F, Kalisch F, Beck-Sickinger AG, Wiedemann P, Reichenbach A, Bringmann A. Glutamate release by neurons evokes a purinergic inhibitory mechanism of osmotic glial cell swelling in the rat retina: activation by neuropeptide Y. J. Neurosci. Res., 83, 538-550 (2006).

31) Wurm A, Lipp S, Pannicke T, Linnertz R, Krügel U, Schulz A, Färber K, Zahn D, Grosse J, Wiedemann P, Chen J, Schöneberg T, Illes $\mathrm{P}$, Reichenbach A, Bringmann A. Endogenous purinergic signaling is required for osmotic volume regulation of retinal glial cells. $J$. Neurochem., 112, 1261-1272 (2010).

32) Kawamura H, Sugiyama T, Wu DM, Kobayashi M, Yamanishi S, Katsumura K, Puro DG. ATP: a vasoactive signal in the pericytecontaining microvasculature of the rat retina. J. Physiol., 551, 787-799 (2003)

33) Sugiyama T, Oku H, Komori A, Ikeda T. Effect of P2X7 receptor activation on the retinal blood velocity of diabetic rabbits. Arch. Ophthalmol., 124, 1143-1149 (2006).

34) Reigada D, Lu W, Zhang M, Mitchell CH. Elevated pressure triggers a physiological release of ATP from the retina: Possicle role for pannezin hemichannels. Neuroscience, 157, 396-404 (2008).

35) Beckel JM, Argall AJ, Lim JC, Xia J, Lu W, Coffey EE, Macarak EJ, Shahidullah M, Delamere NA, Zode GS, Sheffield VC, Shestopalov VI, Laties AM, Mitchell CH. Mechanosensitive release of adenosine 5'-triphosphate through pannexin channels and mechanosensitive upregulation of pannexin channels in optic nerve head astrocytes: a mechanism for purinergic involvement in chronic strain. Glia, 62, 1486-1501 (2014). 